TITLE:

\title{
Musty odor of entomopathogens enhances disease-prevention behaviors in the termite coptotermes formosanus.
}

\author{
AUTHOR(S): \\ Yanagawa, Aya; Fujiwara-Tsujii, Nao; Akino, \\ Toshiharu; Yoshimura, Tsuyoshi; Yanagawa, \\ Takashi; Shimizu, Susumu
}

\section{CITATION:}

Yanagawa, Aya ... [et al]. Musty odor of ento mopathogens enhances disease-prevention behaviors in the termite Coptotermes formosanus.. Journal of invertebrate pathology 2011, 108(1): 1-6

ISSUE DATE:

2011-09

URL:

http://hdl.handle.net/2433/149284

\section{RIGHT:}

(C) 2011 Elsevier Inc.; This is not the published version. Please cite only the published version.; この論文は出版社版でありません。引用の際に は出版社版をご確認ご利用ください。 
1 TITLE: Musty odor of entomopathogens enhances disease-prevention behaviors in the termite Coptotermes

2 formosanus

3 AUTHORS: Aya Yanagawa ${ }^{1)}$, Nao Fujiwara-Tsujii ${ }^{2)}$, Toshiharu Akino ${ }^{3)}$, Tsuyoshi Yoshimura ${ }^{1)}$, Takashi

4 Yanagawa $^{4)}$ and Susumu Shimizu ${ }^{5)}$

5 AFFILIATIONS:

6 1) Research Institute for Sustainable Humanosphere, Kyoto University, Uji 611-0011, Japan

7 2) National Institute of Agrobiological Science, Ohwashi, Tsukuba, 305-0851, Japan

8 3) Chemical Ecology Laboratory, Kyoto Institute of Technology, Matsugasaki, Kyoto 606-8585, Japan

9 4) Biostatistics Centre Kurume University, Fukuoka, 830-0011, Japan

10 5) Institute of Biological Control, Graduate School of Bioenvironmental Science, Kyushu University, Fukuoka,

11 812-8581, Japan

12

13

14 FOOTNOTES TO THE TITLE: Fungal odor enhances termite disease-prevention behavior.

0011, Japan

E-mail: ayanagawa@rish.kyoto-u.ac.jp 


\section{Key Words}

Metarhizium anisopliae, Beauveria brongniartii, Isaria fumosoroseus, SPME, fungal odor, Coptotermes

formosanus Shiraki, disease-prevention behavior

\section{Abstract}

Termites often eliminate pathogens directly through mutual grooming, and are thereby prevent

infections from entomopathogenic fungi. Our previous study confirmed that the antennae of Coptotermes

termite behavior, especially on conidia removal. The musty odor was prepared as an aqueous solution by

\section{Introduction}


Swanson et al., 2009). Mutual grooming behavior, which has been well studied in termites, is a typical hygiene

behavior (Kramm and West, 1982; Boucias et al., 1996; Shimizu and Yamaji, 2003). Through mutual grooming,

their alimentary tract (Yanagawa and Shimizu, 2007; Chouvenc et al., 2009). When together with nest mates,

mutual grooming reduces the chances of termites getting infected by entomopathogenic fungi. This aspect of

termite behavior is one of the key reasons that control of termite populations with entomopathogenic fungi had

so far only limited if any effect. Since such biological approaches are an environment-friendly alternative to the

current chemical control (Verma et al., 2009), it is important to identify the cues that induce termite hygiene

behavior. Although microbes vary greatly with regard to competitive strength, attachment pattern, germination

ability, environmental adaptability, and so on (Clarkson and Charnley, 1996), it is not yet clear what cues lead

termites to notice the presence of entomopathogenic fungi on the cuticle of their nestmates. 


\section{Materials and methods}

\subsection{Insects}

Matured workers of $C$. formosanus were obtained from a laboratory colony maintained since 2002

(Okayama, Japan) in the dark at $28{ }^{\circ} \mathrm{C}$ and more than $85 \%$ R.H. at Kyoto University, Japan. Termites were

separated into two groups, A and B, and each group was placed in a Petri dish $(90 \times 15 \mathrm{~mm})$. At the center of the dishes was a filter paper (about $90 \mathrm{~mm}$ in diam., Whatman No.1) that was impregnated with distilled water (group A) or an aqueous solution of $0.05 \%$ (wt/wt) Nile blue A (group B). They were then kept at $25^{\circ} \mathrm{C}$ for 1 to 2 weeks before use in the bioassay. This treatment stained all of the termites in group B blue.

\subsection{Preparation for collecting fungal odor}

Three isolates of highly virulent entomopathogenic fungi, M. anisopliae 455, I. fumosorosae $\mathrm{K} 3$ and $B$.

brongniartii 782, and three low-virulence isolates, M. anisopliae UZ, I. fumosorosae 8555 and B. bassiana

F1214 were selected. Termites show 90-100\% mortality on highly virulent fungi and 10-50\% mortality on low

virulent fungi at 7 days after treatment, and there are 10- to 100 -fold difference in $\mathrm{LC}_{50}$ between lower- and

higher- virulence fungi when 5 termites are kept in a dish (for further information see Yanagawa and Shimizu

2005; Yanagawa et al., submitted).

All of the Metarhizium, Isaria and Beauveria fungi were maintained on L-broth agar (1\% polypeptone,

$0.3 \%$ yeast extract, $2.0 \%$ sucrose, $0.5 \% \mathrm{NaCl}, 2.0 \%$ agar) at $25{ }^{\circ} \mathrm{C}$. Entomopathogenic fungal conidia were 
74 conidial suspensions were left overnight at $25^{\circ} \mathrm{C}$ and the conidia were then removed through a $0.2 \mu \mathrm{m}$ filter unit (Dismic-13CP, Advantec, Japan). Volatiles trapped in these filtered solutions were used for fungal odor. prepared by gently washing the surface of solid L-broth agar that had not been inoculated with

suspensions, which contained $1.59 \times 10^{7}-3.94 \times 10^{8}$ conidia/ml, could be collected from one culture. The One $\mathrm{ml}$ of distilled water was prepared as control solution W. Another distilled water solution was entomopathogenic fungi as control solution L. These two control solutions were left overnight and filtered as described above.

\subsection{Comparison of grooming behavior among the 6 isolates}

In this assay, groups of four workers treated with control solution and one worker treated with fungus

odor were kept in a Petri dish $(35 \times 15 \mathrm{~mm})$ and their touching frequency was monitored. The odor-treated

termites were taken from the blue-stained termite group B, all termites treated with control solution originated

from the unstained group A. As a control, one termite in group B was treated with control solution $\mathrm{W}$ or L and added to four termites from group A treated with control solution $\mathrm{W}$, and their touching frequency was estimated.

For treatment, termites were collected from the Petri dishes and put in $1 \mathrm{ml}$ microcentrifuge tubes containing a fungus-odor solution. The termites were submerged in the solution with gentle swirling for 5 seconds and allowed to dry on Whatman filter paper. The treated termite groups were then partitioned into the 
91 dishes. After treatment, five termites were placed in Petri dishes and covered with a cardboard box during the experiment to reduce the effect of room light on termite movements. The termites were then left for 15 minutes to reduce the impact of the artificial treatment. Since it was impractical to observe and estimate the level of grooming behavior for the entire duration of termite activity, the frequency at which the termites touched each other was counted on photographs taken every $30 \mathrm{sec}$ for $15 \mathrm{~min}$. Only termites for which the mouth parts touched their nestmates were counted. A total of 30 photographs were taken per dish to clarify differences in grooming behavior among the 6 isolates in addition to the two control solutions. Data were obtained from 20 replicates, thus 800 termites were used.

\subsection{Comparison of disease-preventive behaviors and other responses}

Daily observation of other hygiene behaviors was conducted using the same assay model as described

above; four termites treated with control solution from group A were allowed to contact a single fungus odor-

treated nestmate from group B, and their behaviors were observed. Dead individuals were not removed and the

responses of other termites to the dead individual were also observed. Attack, cannibalism, burial and death

caused by contact with the odor-treated termite in a dish were observed for a week, and the number of dead

individuals and the duration until the first dead individual was found were estimated. The death rate was

calculated both for all of the individuals in a dish and for only the odor-treated individual in a dish. Attacks were determined by the loss of body parts, and therefore cannibalism only included the eating of a dead body. As a 
111 placed in a dish. Data were obtained from 20 replicates. containing odor substances for $30 \mathrm{~min}$ at room temperature. 
compounds were identified by comparison to the mass spectra and retention times of authentic compounds,

which were purchased from Nacalai Tesque (Kyoto, Japan).

\subsection{Statistical analysis}

GENMOD, SAS institute, 1999) was applied. For the analysis of behavioral differences and the number of dead

until the first dead individual was found, was analyzed by a Cox regression model using JMP 6.0 software (SAS).

\section{Results}


144 included termites treated with control solutions $\mathrm{W}$ and $\mathrm{L}(\mathrm{p}=0.077$ in Fig.1 $\mathrm{A}, \mathrm{p}=0.517$ in Fig. $1 \mathrm{~B})$. On the

145 other hand, the touching frequencies in a dish containing a fungus odor-treated termite were significantly greater

146 than those of the two controls (Fig. 1 A. p < 0.001 in Table 1(a); fungal odor parameter). Significant differences

147 in touching frequency were observed among the genera (Metarhizium, Isaria and Beauveria; $\mathrm{p}<0.001$ in Table

1(a); genus parameter) and isolates (M. anisopliae UZ, M. anisopliae 455, I. fumosorosae 8555, I. fumosorosae

K3, B. bassiana F1214 and B. brongniartii 782; p $<0.001$ in Table 1(a); isolate parameter) in odor-treated

groups. However, though the frequency at which other termites touched the treated termite in a mixed group was

clearly greater than that in the control (Fig. 1B, p $<0.001$ in Table 1(b); fungal odor parameter), no difference

parameters). The odor substances induced high levels of grooming activity.

\subsection{Comparison of disease-preventive behaviors and other responses}

treatment (Table 3, p < 0.015; fungal odor parameter). While this increase in attack behavior was specific to the 

$\mathrm{p}=0.169 ;$ fungal odor parameter, respectively). difference was seen in the survival time until the first dead individual was discovered (Fig. 4 and Table 3, p = 0.166; fungal odor parameter).

shown in Fig. 1. 3-Octanone, 3-octanol and 1-octen-3-ol (1; RT = $9.2 \mathrm{~min}, 2 ; \mathrm{RT}=11.9 \mathrm{~min}, 3$; RT $=12.8 \mathrm{~min}$, 
bassiana F1214. The results of mass spectrometry showed that the chemical was 3-octanol in the two isolates of

Beauveria, but the chemical peak in I. fumosorosae K3 could not been identified (* in Fig. 5).

\section{Discussion}

The volatile odor of pathogenic fungi significantly increased termite grooming and attack behavior, which

resulted in an increased number of dead individuals. On the other hand, there were no changes in cannibalism or

burial behavior. This suggests that cannibalism and burial behavior are induced by signals after infection, rather

than by the pathogen itself. These results indicate that odor information affects behavior in the termite $C$.

formosanus. Presence of spores on a termite body may also trigger grooming and attack behaviors. There are

certainly differences in response to Metarhizium spore by nestmates depending on whether the isolate is virulent

prior to infection. However odor triggers the remarkable responses as detailed in this study.

A and Table 1 (a); $\mathrm{p}<0.001$; genus and isolate parameters), but all termites carrying odor were groomed at 
reported an increase in pathogen alarm behavior by the termite Zootermopsis angusticollis using M. anisopliae.

In their study, termites were not allowed to directly contact treated individuals, and they showed an enhanced

pathogen. In our study, attack behavior and the number of dead individuals also increased by having the fungal

odor-treated nestmate in the population (Table 3; fungal odor parameter for attacks and number of deaths).

According to Myles (2002), alarm, grooming, attack and burial behaviors occur as an interactional sequence. In

contrast, our results suggest that these behaviors may be regulated by different neural mechanisms, since burial and cannibalism behaviors were not enhanced by treatment with the fungal odor solution (Table $3, p=0.055$ and $\mathrm{p}=0.169$; fungal odor parameter for burial and cannibalism, respectively). For grooming to be effective as a preventive strategy, it has to be triggered as early as possible. Most effective would be to respond simply due to the presence of fungal conidia or their odor. Grooming and attacking behaviors are probably enhanced by signals before infection, and cannibalism and burial behavior are enhanced by signals after infection. These chemical compounds, which induce aggressive behavior in termites, may lead to new strategies for managing termites. complicated. For example, in Metarhizium, dead individuals were only found with the weak virulent UZ isolate, 
$216 \quad \mathrm{~K} 3$ and 782 (Fig. 3). While several studies have reported that termites are repelled by the odor of strongly

217 virulent entomopathogenic fungi (Myles 2002; Mburu et al., 2009), the more isolates one examines the more

the pathogens and high molecular compounds, which will be recognized by gustatory receptors and thus the

interaction between all these factors is still ambiguous. Our results here suggest just that termites cannot identify

differences in virulence solely from their odor. Besides, the observation indicates that odor of dead individuals 
234 odor emission of fungi changes readily depending e.g. on growing conditions, age of the culture etc. Although

235 the chemical composition was quite stable, it was difficult to quantify the collected odors. The methods for

236 quantification and standardization of the fungal odor are necessary for future studies.

\section{Acknowledgements}

for Young Scientists. We thank Dr. K. Tsunoda (RISH, Kyoto University, Japan) for his helpful comments on this study.

\section{References}

244 Boucias, D.G., Stokes, C., Storey, G., Pendland, J.C. 1996. The effects of imidacloprid on the termite Reticulitermes flavipes and its interaction with the mycopathogen Beauveria bassiana. PflanzenschutzNachr. Bayer 49, 103-144.

Clarkson, J.M., Charnley, A.K. 1996. New insights into the mechanisms of fungal pathogenesis in insects. Trends in Microbiol. 4, 197-203.

Chouvenc, T., Su, N-Y., Robert, A. 2009. Inhibition of Metarhizium anisopliae in the alimentary tract of the eastern subterranean termite Reticulitermes flavipes. Journal of Invertebrate pathology 101, 130-136. 
Crespo, R., Cafferata, L.F.R. 2000. Biochemical interaction between entomopathogenic fungi and their insect-

Hallsworth, J.E., Magan, N. 1997. A rapid HPLC protocol for detection of polyols and trehalose. Journal of

Hallsworth, J.E., Magan, N. 1993. Effects of KCL concentration on accumulation of acyclic sugar alcohols and trehalose in conidia of three entomopathogenic fungi. Letters in Applied Microbiology 18, 8-11.

Kramm, K.R., West, D.F. 1982, Termite pathogens: effects of ingested Metarhizium, Beauveria, and Gliocladium conidia on worker termite (Reticulitermes sp.). J. Invertebr. Pathol. 40, 7-11.

Mburu, D.M., Ochola, L., Maniania, N.K., Njagi, P.G.N., Gitonga, L.M., Ndung'u, M.W., Wanjoya, A.K., Hassanali, A. 2009. Relationship between virulence and repellency of Entomopathogenic isolates of Metarhizium anisopliae and Beauveria bassiana to the termite Macrotermes michaelseni. J. Insect Physiol. 55, 774-780.

Myles, T.G. 2002. Alarm, aggregation, and defense by Reticulitermes flavipes in response to a naturally occurring isolate of Metarhizium anisopliae. Sociobiology 40, 243-255. 
Pedrini, N., Crespo, R., Juárez, M.P. 2007. Biochemistry of insect epicuticle degradation by entomopathogenic fungi. Comp Biochem Physiol, Part C 146, 124-137.

Rosengaus, R.B., Jordan, C., Lefebvre, M.L., Traniello, J.F.A. 1999. Pathogen alarm behavior in termite: a new form of communication in social insects. Naturwissenschaften $86,544-548$.

SAS Institute Inc, 1999. SAS 9.1.3 Service Pack 1, SAS Institute Inc., Cary, NC.

Shimizu, S., Yamaji, M. 2003. Effect of density of the termite, Reticulitermes speratus Kolbe(Isoptera: Rhinotermitidae), on the susceptibilities to Metarhizium anisopliae. Jpn. J. Appl. Entomol. Zool. 38, 125-

Swanson, J.A.I., Torto, B., Kells, S.A., Mesce, K.A., Tumlinson, J.H., Spivak, M. 2009. Odorants that induce hygenic behaviour in honeybees: Identification of volatile compounds in Chalkbrood-infected honeybee larvae. J. Chem. Ecol. 35, 1108-1116.

Verma, M., Sharma, S., Prasad, R. 2009. Biological alternatives for termite control: A review. Int. Biodeterioration \& Biodegradation 63, 959-972.

Yanagawa, A., Shimizu, S. 2005. Defense strategy of the termite, Coptotermes formosanus Shiraki to entomopathogenic fungi. Jpn. J. Environ. Entomol. Zool. 16, 17-22.

Yanagawa, A., Shimizu, S. 2007. Resistance of the termite, Coptotermes formosanus Shiraki to Metarhizium anisopliae due to grooming. BioControl 52, 75-85. 
Yanagawa, A., Yokohari, F., Shimizu, S. 2009. The role of antennae in removing entomopathogenic fungi from

cuticle of the termite, Coptotermes formosanus. J. Insect Sci. 9, Article 6.

Yanagawa, A., Yokohari, F., Shimizu, S. 2010. Influence of fungal odor on grooming behavior of the termite,

Fig. 1. Comparison of grooming activity in termite groups of 5 individuals which included a termite treated with

the odor substances of 6 different fungal isolates. A: Frequency of touching between all 5 termites in a dish. B:

Fig. 2. Behavioral changes observed in termites treated with the odor substances of 6 fungal isolates. 
304 Fig. 5. Gas chromatogram of volatiles from A: an empty glass container. B: a glass container containing control

305 solution L. C: a glass container containing $M$. anisopliae 455 odor-solution. D: a glass container containing $M$.

306 anisopliae UZ odor-solution. E: a glass container containing I. fumosorosae K3 odor-solution. F: a glass

307 container containing I. fumosorosae 8555 odor-solution. G: a glass container containing B. bassiana 782 odor-

308 solution. H: a glass container containing B. brongniartii F1214 odor-solution. 

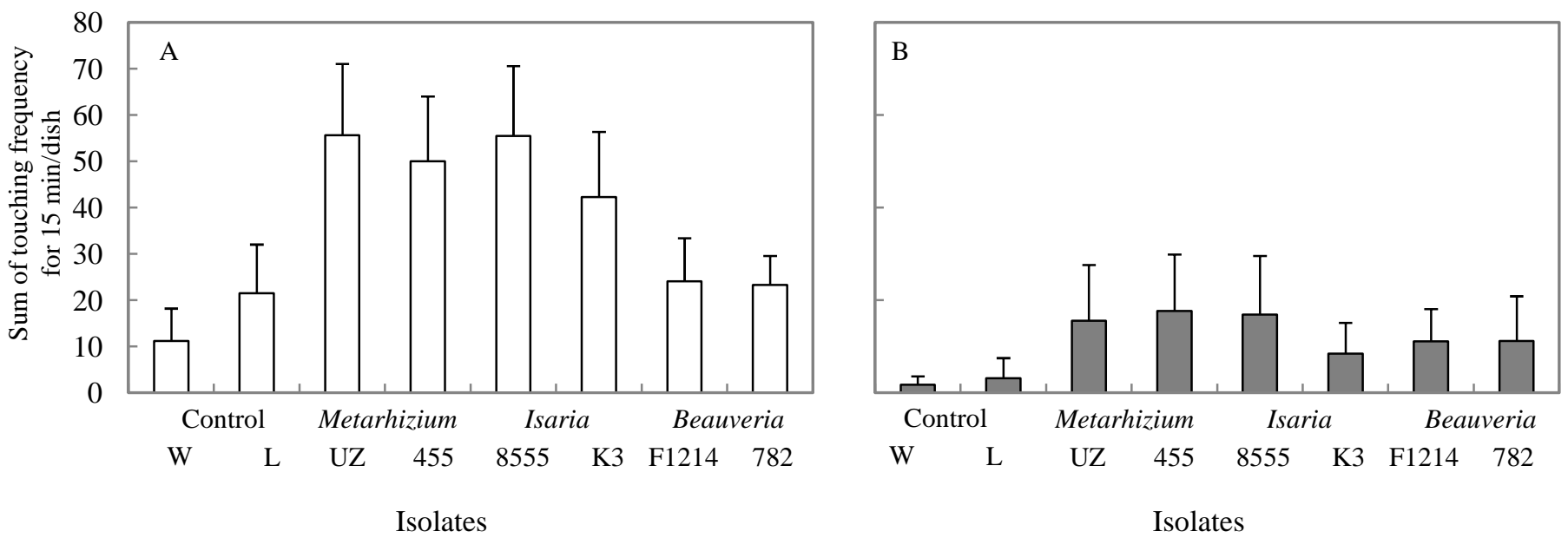

Fig1 


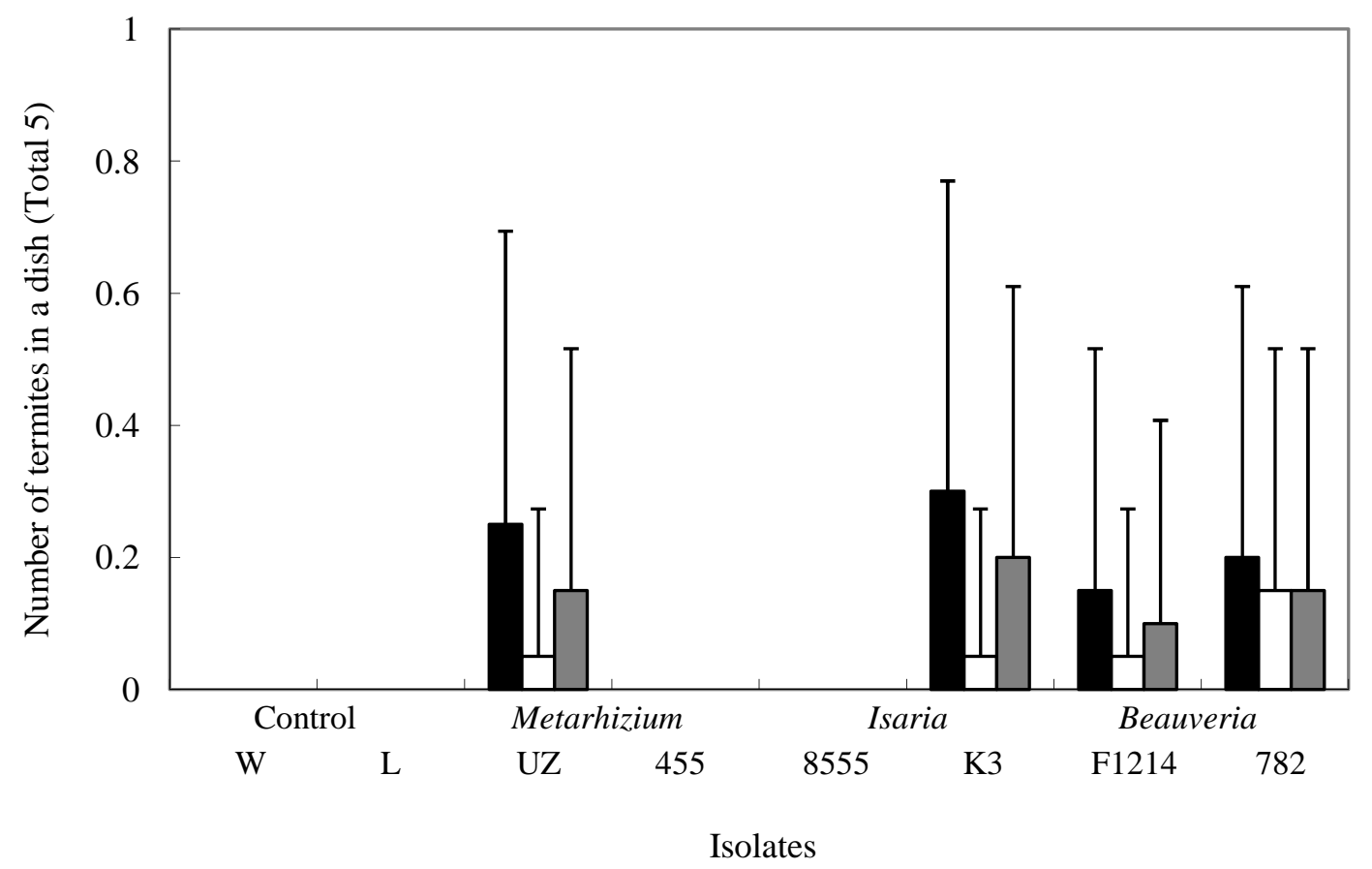

Fig2 


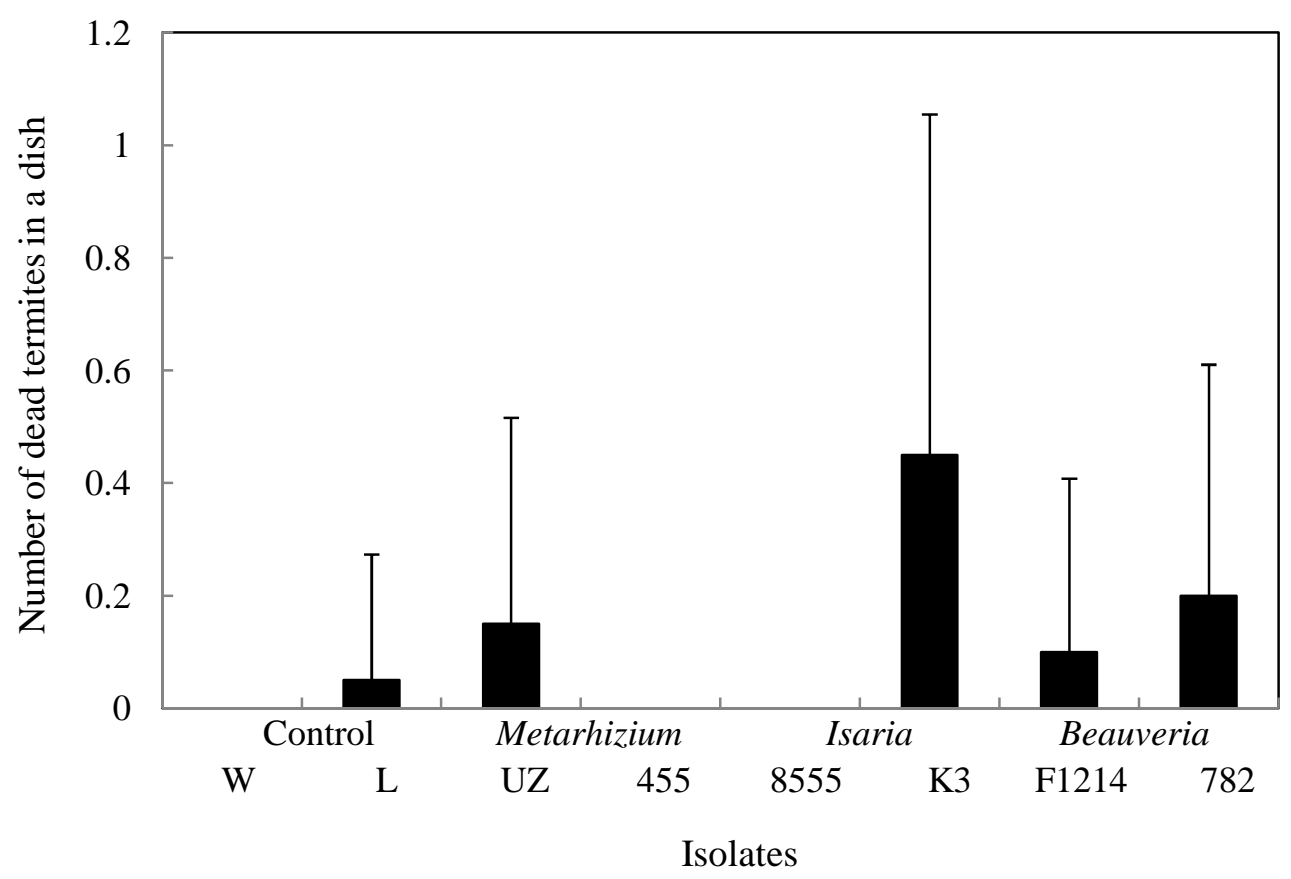

Fig3 


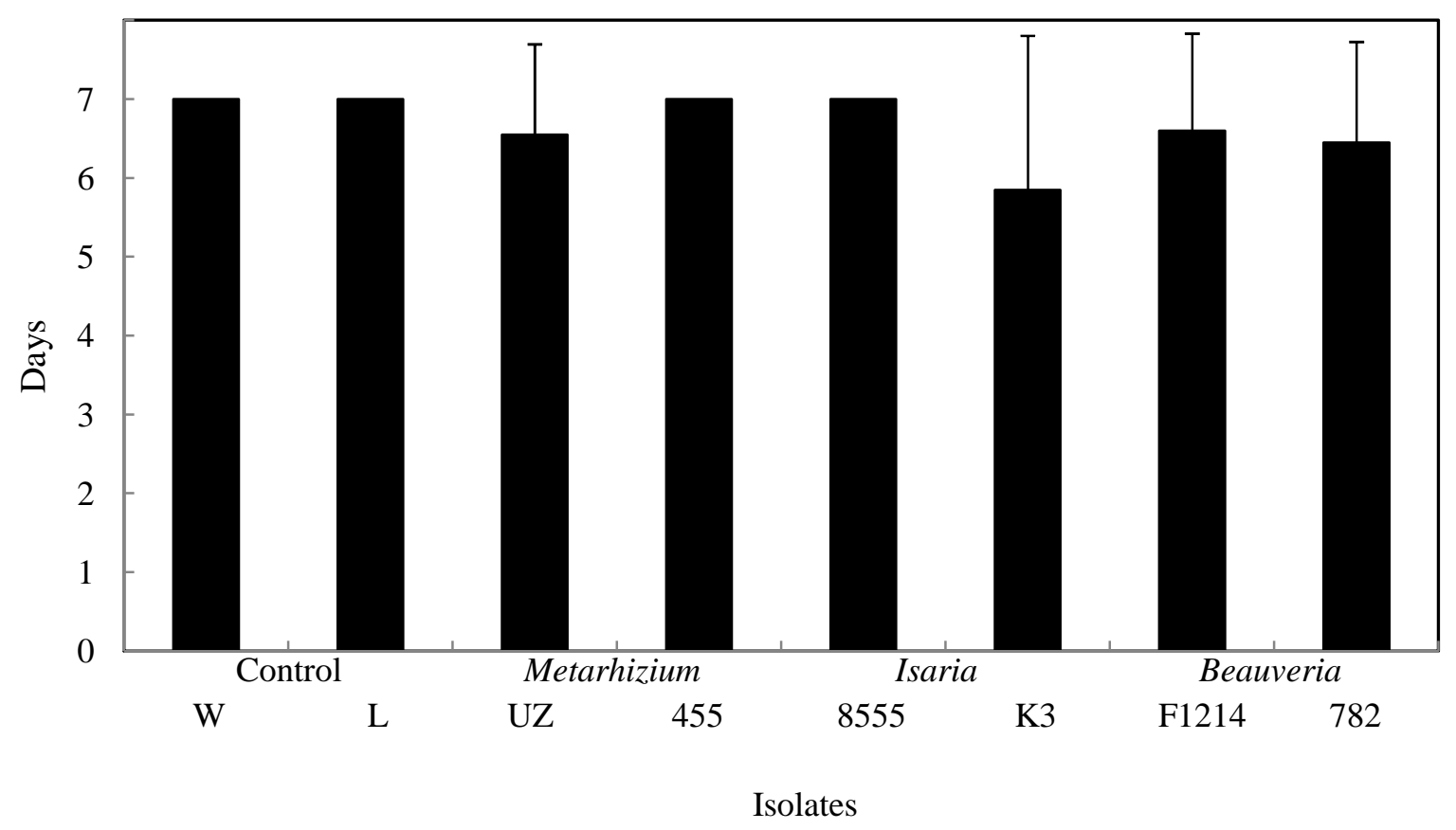

Fig4 
A

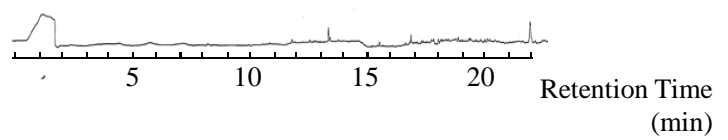

C

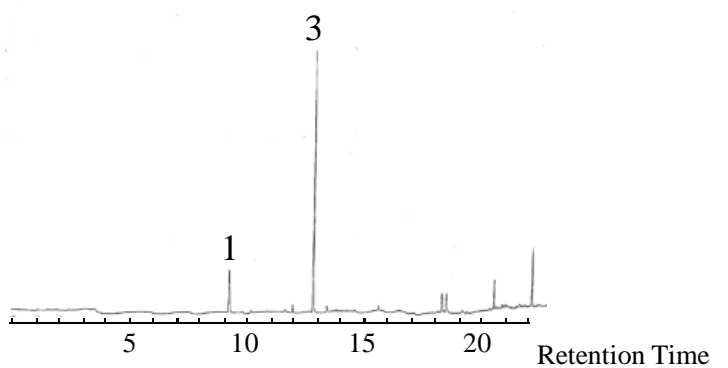

(min)

E

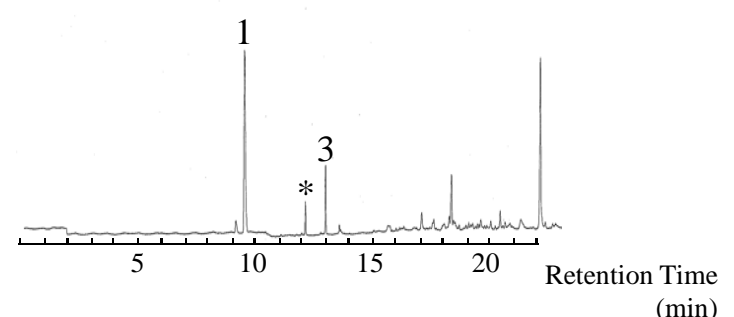

G

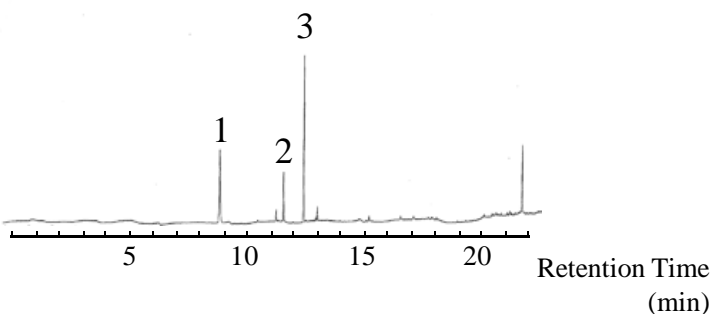

B

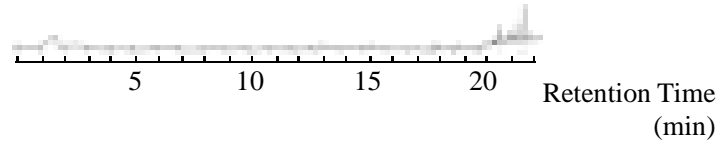

D

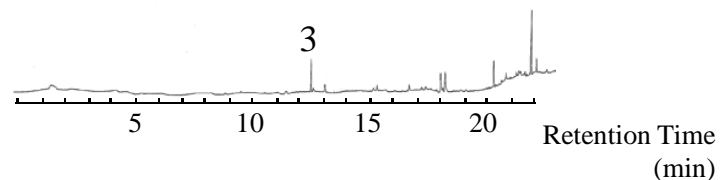

F

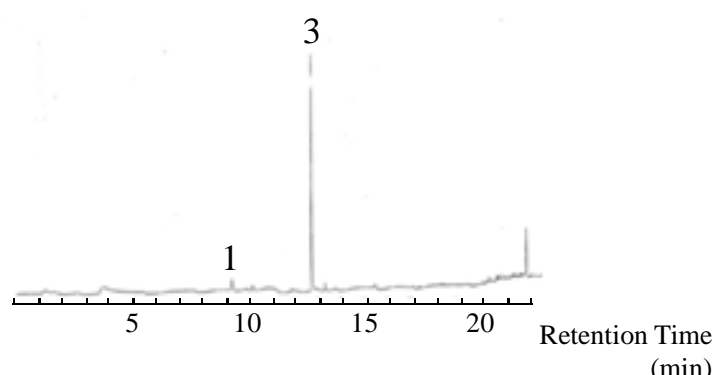

$\mathrm{H}$

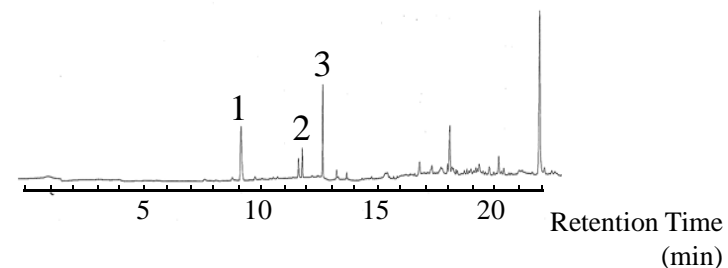


Table 1 Comparison of the frequency of touching (a) between all 5 termites in a dish and (b) of one termite treated with odor from 6 fungal isolates by 4 untreated termites.

Results of Poisson regression

\begin{tabular}{|c|c|c|c|c|c|c|c|}
\hline Parameter & \multirow{2}{*}{$\frac{\mathrm{DF}}{\mathrm{y} \text { of } \mathrm{a}}$} & Estimate & \multirow[t]{2}{*}{$\begin{array}{c}\text { Standard } \\
\text { error }\end{array}$} & \multicolumn{2}{|c|}{$\begin{array}{c}\text { Wald 95\% } \\
\text { confident limit }\end{array}$} & \multirow[t]{2}{*}{$\mathrm{X} 2$} & \multirow[t]{2}{*}{$\operatorname{Pr}><\operatorname{chi}>2$} \\
\hline (a) Touching 1 & & ates in a di & & & & & \\
\hline Fungal odor & 1 & 0.938 & 0.186 & 0.574 & 1.303 & 25.45 & $<0.001$ \\
\hline Genus & 1 & -0356 & 0.080 & -0.513 & -0.120 & 19.92 & $<0.001$ \\
\hline Isolate & 1 & -0.176 & 0.038 & -0.251 & -0.102 & 21.45 & $<0.001$ \\
\hline Virulence & 1 & -0.157 & 0.127 & -0.406 & 0.091 & 1.54 & 0.215 \\
\hline \multicolumn{8}{|c|}{ (b) Touching frequency to one treated termites in a dish } \\
\hline Fungal odor & 1 & 1.714 & 0.468 & 0.798 & 2.631 & 13.45 & $<0.001$ \\
\hline Genus & 1 & -0.204 & 0.138 & -0.474 & 0.066 & 2.19 & 0.139 \\
\hline Isolate & 1 & -0.107 & 0.066 & -0.236 & 0.022 & 2.62 & 0.105 \\
\hline Virulence & 1 & -0.156 & 0223 & -0.594 & 0.281 & 0.49 & 0.484 \\
\hline
\end{tabular}


Table 2 Occurrence of dead termites in 20 replicates

\begin{tabular}{|c|c|c|c|c|c|c|c|c|}
\hline & \multirow[b]{3}{*}{ control } & \multirow[b]{3}{*}{ LB } & \multirow{2}{*}{\multicolumn{2}{|c|}{ Metarhizium }} & \multicolumn{2}{|c|}{ Isolates } & \multirow{2}{*}{\multicolumn{2}{|c|}{ Beauveria }} \\
\hline & & & & & \multicolumn{2}{|c|}{ Peacilomyces } & & \\
\hline & & & UZ & 455 & K3 & 8555 & F1214 & 782 \\
\hline $\begin{array}{c}\text { Total of dead } \\
\text { individuals }(n=100)\end{array}$ & 0 & 1 & 3 & 0 & 9 & 0 & 2 & 4 \\
\hline \multicolumn{9}{|l|}{ First dead individuals } \\
\hline Treated termite & 0 & 0 & $1 / 3$ & - & $3 / 8$ & - & 0 & $2 / 4$ \\
\hline Untreated termite & 0 & $1 / 1$ & $2 / 3$ & - & $5 / 8$ & - & $2 / 2$ & $2 / 4$ \\
\hline \multicolumn{9}{|c|}{ Dead individuals; $\mathrm{n} /$ total dead individuals (rate in termite group\%) } \\
\hline $\begin{array}{l}\text { Treated termite } \\
\quad(\mathrm{n}=20)\end{array}$ & $0(0)$ & $0(0)$ & $1 / 3(5)$ & $0(0)$ & $3 / 9(15)$ & $0(0)$ & $0(0)$ & $2 / 4(10)$ \\
\hline $\begin{array}{l}\text { Untreated termite } \\
\qquad(\mathrm{n}=80)\end{array}$ & $0(0)$ & $1 / 1(1.25)$ & $2 / 3(2.5)$ & $0(0)$ & $6 / 9(7.5)$ & $0(0)$ & $2 / 2(2.5)$ & $2 / 4(2.5)$ \\
\hline
\end{tabular}


Table 3 Comparison of differences in termite responses to odors from 6 fungal isolates.

Results of logistic regression.

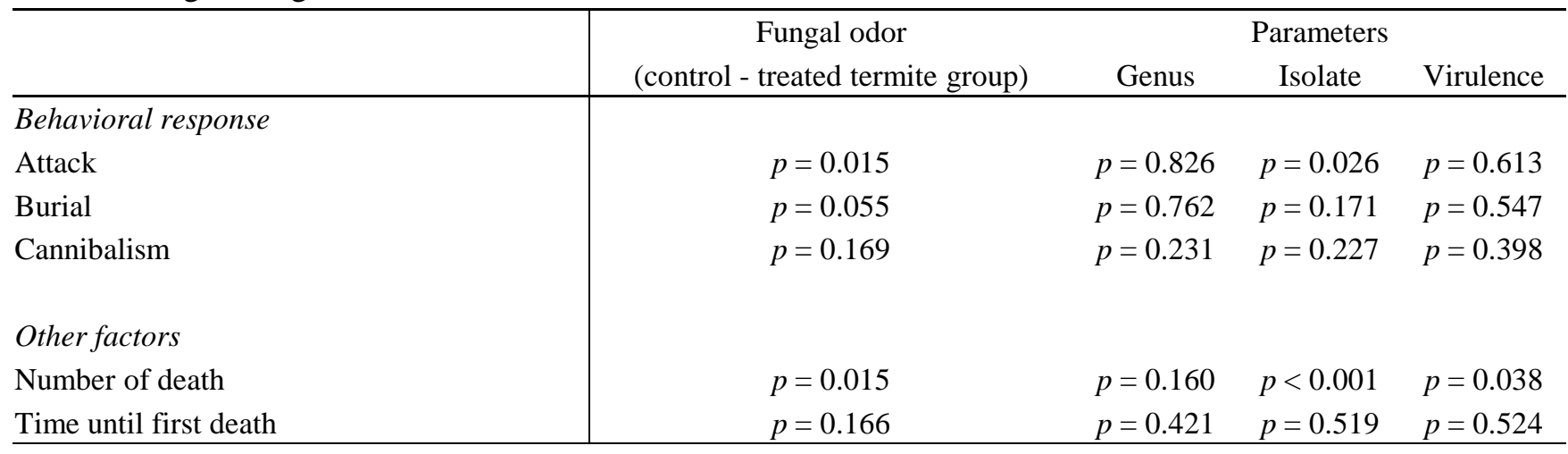

